Volume 15 - Número 2 - ago/dez de 2020

\title{
A INFLUÊNCIA DOS CONECTIVOS ADVERSATIVOS NA LEITURA DE ESTUDANTES GRADUANDOS E DO ENSINO MÉDIO DURANTE O PROCESSAMENTO DE PERÍODOS EM PORTUGUÊS BRASILEIRO
}

\section{THE INFLUENCE OF ADVERSATIVE CONNECTIVES ON READING GRADUATE STUDENTS AND HIGH SCHOOL DURING THE PROCESSING OF PERIODS IN BRAZILIAN PORTUGUESE}

\author{
Antonia Barros Gibson Simões ${ }^{1}$ \\ Márcio Martins Leitão ${ }^{2}$ \\ Henrique Miguel de Lima Silva ${ }^{3}$ \\ Danielli Cristina de Lima Silva ${ }^{4}$
}

\begin{abstract}
RESUMO: Esta pesquisa investigou a influência dos conectivos adversativos no processamento de períodos em português brasileiro durante a leitura de leitores graduandos e de ensino médio. Com base na frequência de uso de conectivos (CROSSON et. al., 2008), no Modelo Estratégico de Processamento (DIJK e KINTISCH, 1983), na observação sobre a facilitação na leitura de textos com conectivos (MILLIS E JUST, 1994), e no tipo de relação de coerência manifestado pelo conectivo (SANDERS \& NOORDMAN, 2000; TRAXLER et.al., 1997; MURRAY, 1997; CROSSON et.al., 2008), dois experimentos foram realizados. No experimento 1, com tarefa on-line de leitura automonitorada (movie window), teste de familiaridade e questionário sobre o perfil do leitor, investigamos o papel dos conectivos no processamento textual observando a influência de conectivos adversativos e da frequência de uso de conectivos adversativos na leitura de graduandos em textos com e sem os conectivos mas, porém, e, todavia. No experimento 2, utilizamos o mesmo design experimental e tarefas off-line do experimento 1, entretanto, os leitores eram do ensino médio. Fundamentados no mapeamento da leitura da parte inicial e final de proposições antecedidas ou não por conectivos adversativos, concluímos que a existência desses conectivos facilitou a leitura de períodos e, também, a recuperação do conteúdo do texto. Além disso, o papel dos conectivos foi influenciado pela frequência de uso e familiaridade do leitor com os conectivos investigados e pela idade/nível de escolaridade do leitor. A Psicolinguística Educacional, por meio de tarefa experimental on-line e off-line, pode auxiliar os docentes na avaliação sobre processo de conhecimento/aprendizagem dos alunos sobre assuntos relacionados à leitura/compreensão de recursos de coesão e de coerência textual.
\end{abstract}

PALAVRAS-CHAVE: Conectivos, processamento de períodos, frequência, Psicolinguística Educacional.

ABSTRACT: This research aims at investigating the processing of adversative connectors in Brazilian Portuguese reading task of undergraduate and high school students. Considering the frequency of use of connectors (CROSSON et. Al., 2008), in the Strategic Processing Model (DIJK and KINTISCH, 1983),

\footnotetext{
${ }^{1}$ Doutora em Linguística pelo Programa de Pós-Graduação em Linguística da Universidade Federal da Paraíba PROLING - UFPB. Membro do LAPROL - Laboratório de Processamento Linguístico. E-mail: antoniagibson@gmail.com.

${ }^{2}$ Pós-Doutor em Linguística pela Universidade de Lisboa; Doutor em Linguística pela UFRJ, Professor Associado do Departamento de Língua Portuguesa e Linguística e do Programa de Pós-Graduação em Linguística (PROLING) da UFPB. Projeto realizado com auxílio do CNPq (Edital Bolsa de Produtividade e Pesquisa - PQ 09/2018 Processo 309130/2018.2). E-mail: profleitao@gmail.com. ORCID: https://orcid.org/0000-0003-23851636

${ }^{3}$ Doutor em Linguística pelo Programa de Pós-Graduação em Linguística da Universidade Federal da Paraíba PROLING - UFPB. Professor adjunto do Departamento de Língua Portuguesa e Linguística e docente permanente do Programa de Pós-Graduação em Linguística e Ensino - PGLE da UFPB. E-mail: Henrique.miguel.91@gmail.com. ORCID: https://orcid.org/0000-0002-1394-9173

${ }^{4}$ Mestre em Linguística pelo Programa de Pós-Graduação em Linguística da Universidade Federal da Paraíba PROLING - UFPB. Membro do LAPROL - Laboratório de Processamento Linguístico. E-mail: limaanacrisdani@gmail.com.
} 
as well as the observation about the readability of texts with-out connectors (MILLIS E JUST, 1994), and, finally, the type of coherence relationship manifested by the connective clauses (SANDERS \& NOORDMAN, 2000; TRAXLER et.al., 1997; MURRAY, 1997; CROSSON et.al., 2008), we tested our hypothesis in two experiments. In experiment 1, there were three activities: a) self-paced reading (movie window), b) familiarity task and c) questionnaire about the reader's profile. In addition, we investigated the role of connectives in textual processing by observing the influence of adversative connectives and the frequency of use of adversative connectives in reading task of undergraduate students with and without connectors. In experiment 2, we applied the same experimental materials and tasks as experiment 1 on high school students. Analyzing the reading maps of the initial and final part of propositions preceded or not by adversative connectors, we shall conclude that the existence of these connectors facilitated the reading of periods and, also, the recovery of the text content. In addition, the role of the connectors was influenced by the frequency of use and the reader's familiarity with the investigated connectors and the reader's age / level of education. Educational Psycholinguistics, through online and offline experiments, can assist teachers in assessing students' knowledge / learning process on subjects related to reading / understanding cohesion and textual coherence resources.

KEYWORDS: Connectives. Period processing. Frequency. Educational Psycholinguistics.

\section{Introdução}

Os recursos de coesão, do tipo conectivos, manifestam explicitamente como o leitor deverá relacionar as partes compositoras de um texto. São, portanto, fundamentais no processo de obtenção da coerência textual. De acordo com o princípio da coerência, as partes compositoras do texto precisam se harmonizar no sentido. Em busca do sentido do texto, o movimento natural do leitor é procurar links entre os itens linguísticos manifestados no texto.

Assumindo que no processo de compreensão textual construímos uma representação mental do texto (DIJK e KINTSCH, 1983) - que seria, basicamente, uma tentativa de atribuição de significado durante o processamento textual- e o princípio norteador dessa construção é a coerência (KOCH e TRAVAGLIA, 2009; MARCUSCHI, 2008; DIJK e KINTSCH, 1983), fazemos uso da estratégia da coerência local objetivando relacionar os itens textuais, sendo os conectivos, segundo Dijk e Kintsch (1983), muito importantes nesse tipo de estratégia.

O modelo de processamento estratégico de Dijk e Kintsch (1983) propõe que os leitores realizam hipóteses efetivas, sobre a estrutura e conteúdo textual, durante a leitura, culminando com a construção da representação mental do texto. As hipóteses efetivas são fundamentadas, também, pela estratégia da coerência local. A existência de conectivos em determinado momento do texto, por exemplo, apoia previsões sobre a estrutura e o conteúdo dos itens linguísticos que aparecerão após esse recurso de coesão textual.

De certa forma, a realização de hipóteses efetivas pode ser relacionada à capacidade de o leitor fazer predições sobre os próximos inputs a serem processados em um evento de comunicação. Neste caso, prever é realizar mapeamentos. Os leitores, durante a compreensão de períodos, construirão relações entre a estrutura do período e a estrutura do evento correspondente. Estas relações permitem fundamentar antecipações sobre inputs vindouros, sendo estas apoiadas pela previsibilidade, de estrutura e conteúdo, espelhada na língua (ALTMAN \& MIRKOVIC, 2009).

Os conectivos parecem modular a construção da representação do período por causa de suas pistas informacionais, por isso a importância de investigarmos o papel desses recursos de coesão no processamento da linguagem. Objetivando investigar a influência dos conectivos no processamento de períodos em português brasileiro, elegemos a relação de coerência adversativa- importante por revelar explicitamente a manifestação de descontinuidade do evento textual antecedido por este tipo de conectivo- e construímos um design experimental 
formado por tarefa on-line, em que registramos o tempo de leitura de cada segmento das proposições formadoras do período textual lido pelos sujeitos participantes dos experimentos. Também realizamos tarefas off-line sendo estas formadas por teste de familiaridade e questionário sobre o perfil do leitor.

O papel da existência de conectivos em textos foi observado, em dois experimentos, durante a leitura de textos por estudantes graduandos e do ensino médio e os resultados foram interpretados a partir do modelo estratégico de processamento- especificamente com a estratégia de coerência local-, do efeito de facilitação na leitura de textos com conectivos e da influência da frequência de uso no processamento de textos com conectivos.

Parte do processo de ensino é fundamentado na leitura de textos. É relevante, portanto, perceber quais elementos linguísticos podem auxiliar o discente no processo de compreensão textual. Os resultados obtidos por meio dos experimentos a serem relatados no presente artigo, como a confirmação da hipótese de efeito de facilitação na leitura promovida pela existência de conectivos adversativos e a influência da frequência de uso desses conectivos, por exemplo, podem fundamentar a construção de intervenções educacionais levando-se em conta esse tipo de recurso de coesão. A existência do diálogo entre Psicolinguística e Educação Psicolinguística Educacional - representa uma forma de inserir a metodologia experimental como uma ferramenta pedagógica capaz de trazer contribuições ao processo de ensino/aprendizagem, como os trabalhos realizados no âmbito do Laboratório de Eletroencefalografia e rastreamento ocular (LER) da UFRJ que mapeou fenômenos de processamento relacionados a habilidades leitoras, como também construiu posteriormente intervenções eficazes no âmbito da escola (MAIA, 2019), esses trabalhos serviram de inspiração para este nosso estudo inicial que focaliza essa interface com a Educação.

\section{A estratégia da coerência local na construção da representação mental do texto}

Os leitores, com o objetivo de construir uma representação mental do texto, a partir de fragmentos textuais, aplicam estratégias. As estratégias, para Dijk e Kintsch (1983), podem ser consideradas hipóteses efetivas sobre a estrutura e significados corretos de um determinado texto.

Os conectivos são importantes, estrategicamente, para a compreensão de um texto pois “[...] são os mais eficazes sinais para manifestar a relação entre os fatos” (DIJK, 1980, p. 11), sendo fundamentais para o estabelecimento da coerência, já que os leitores precisam relacionar os fatos para construir uma representação adequada (coerente) do significado do texto.

$\mathrm{Na}$ estratégia da coerência local, os leitores, objetivando a compreensão textual, assumem que as partes compositoras do texto são coerentes. A coerência textual é apoiada, também, pelas relações existentes entre as partes que formam o texto. Estas relações, segundo Dijk e Kintsch (1983), são apoiadas (confirmadas) pela existência de conectivos na estrutura superficial do texto. Há, na estratégia de coerência local, uma pressuposição de natureza geral: assume-se que as próximas proposições a serem lidas manifestam os eventos/ações/estados resultantes (DIJK e KINTSCH, 1983, p.43):

\section{(1) John went to station. He bought a ticket ${ }^{5}$.}

No texto (1), não há um marcador relacional explícito entre as duas proposições, quais sejam, John went to station e He bought a ticket. Entretanto, não há prejuízo para a compreensão textual porque, segundo, Dijk e Kintsch (1983), a relação entre as proposições é clara.

\footnotetext{
5 “John foi para a estação. Ele comprou uma passagem” (tradução nossa).
} 
Quando não há uma relação clara entre proposições é necessário haver itens linguísticos indicando ao leitor que a relação entre duas proposições não é um caso claro de um evento/ação/estado resultante. Analisemos mais um exemplo (DIJK, p.41, 1981):

(2) I had a car accident yesterday. The brakes did not work ${ }^{6}$.

Em (2), não há conectivo relacionando as duas proposições, além disso, a situação The brakes did not work não pode ser interpretada como um resultado da situação I had a car accident yesterday, mas sim como condição para determinado acontecimento. Para Dijk (1981), o link de coerência em (2) é funcional. Neste caso, o leitor deverá perceber que a relação entre o fato prévio e o fato novo é particular. O conectivo, manifestado explicitamente, poderia indicar para o leitor essa informação. É como se o conectivo sinalizasse para o leitor que a compreensão do texto não dependerá somente da identificação de participantes e possíveis consequências manifestadas entre os fatos (DIJK, 1981).

Segundo Dijk (1981), diante de duas proposições, depois de o leitor ler a primeira proposição é provável que ele espere, na segunda proposição, um evento que manifeste um resultado (consequência, causa). Essa é a relação esperada, é uma pressuposição de natureza geral. Da mesma maneira, Altmann e Mirkovic (2009) apontam a causalidade como fundamento para um modelo de surgimento da estrutura de eventos.

Para Altmann e Mirkovic (2009), um modelo de surgimento de estruturas de eventos deve manifestar as representações que captem a percepção da causalidade nos seres humanos. $\mathrm{O}$ surgimento da estrutura de eventos emerge a partir da sensibilidade às possibilidades temporais entre um estado atual e um estado futuro. Prever estados posteriores a partir de estados anteriores é uma manifestação dessa sensibilidade, a predição seria a chave para o surgimento da estrutura de eventos (ALTMANN E MIRKOVIC, 2009).

Para Dijk e Kintsch (1983), o leitor não espera até o fim do texto para construir a sua representação mental. $\mathrm{O}$ modelo estratégico de processamento prevê ações/procedimentos para compreensão de textos como procurar links e hipotetizar sobre próximas estruturas/conteúdo do texto. O modelo de Altmann e Mirkovic (2009) engloba um sistema incremental em que fragmentos do período são responsáveis pelo fornecimento de informações completas (sobre estrutura/conteúdo) e possíveis continuações textuais. Os conectivos parecem indicar ao leitor possíveis estruturas e conteúdo da proposição que o segue.

Noordman e Vonk (2014), por sua vez, apontam para três funções de um conectivo e, a partir delas, explicam como acontece o processamento textual e como acontece a construção da representação textual. As três funções dos conectivos, quais sejam, segmentar, integrar e promover o processo inferencial também dialogam de maneira harmônica com a possibilidade de esses tipos de recursos de coesão promoverem processos de construção de hipótese efetivas e predições sobre as partes do texto que ainda não foram lidas.

Os conectivos dão instruções ao leitor sobre o texto. A primeira instrução, relacionada à função sintática do texto, é a de segmentação. Isto significa: a partir do momento da leitura do conectivo, o leitor saberá que depois dele haverá outra oração. Neste sentido, a função da conjunção é direcionar a atenção da oração anterior para a próxima oração. A função de segmentador dos conectivos está relacionada, portanto, a parte organizacional/estrutural do texto.

Convém destacar que os conectivos têm, também, a função de integrar o texto. A função integradora nos revela que: "[...] a presença de uma conjunção indica explicitamente como a sentença atual tem de ser integrada com a sentença prévia. Leitores não tem de computar a relação entre a sentença puramente com base nas proposições das sentenças; eles são ajudados

\footnotetext{
6 "Eu tive um acidente de carro ontem. Os freios não funcionaram” (tradução nossa).
} 
pela conjunção (NOORDMAN \& VONK, p. 77, 2014, tradução nossa). O conectivo indica ao leitor que a informação atual deverá ser relacionada/integrada à informação anterior de determinada maneira. Por exemplo, ao ler o conectivo $b u t^{7}$, o leitor é instruído a construir um contraste entre a oração que foi lida e a oração que será lida.

A função inferencial requer que o leitor, a partir da dedução de relações entre os conteúdos propostos pelo texto, faça uma "consulta" ao seu conhecimento de mundo para verificar/checar as proposições (e as relações entre as proposições) contidas no texto.

O leitor, ao ter instruções de como poderá se estruturar e como deverá se integrar a proposição que virá depois do conectivo, tem a leitura facilitada. $\mathrm{O}$ efeito de facilitação da leitura de proposições seguindo conectivos, que pode ser observado nos tempos de leitura em tarefas experimentais online, manifesta o papel desses recursos de coesão como itens linguísticos capazes de fundamentar as hipóteses efetivas e predições sobre as proposições que ainda não foram lidas. Além disso, a questão da frequência/familiaridade do leitor com o conectivo adversativo e, também, a influência do tipo de relação de coerência estabelecida pelo conectivo são fatores que podem agregar informações relevantes na nossa investigação, motivo pelo qual foram incluídos na nossa pesquisa.

\section{Processamento de conectivos: efeito de facilitação na leitura de textos}

Millis e Just (1994), propõem que a informação contida na primeira oração de um texto será ativada em maior grau, em um texto com conectivo quando comparada com a ativação da primeira oração de um texto inexistindo um conectivo relacionando as duas proposições. É a chamada hipótese de reativação (Reactivation Hypothesis).

Utilizando a técnica experimental de leitura automonitorada (movie-window display), os autores examinaram o efeito da existência do conectivo no nível de ativação da oração anterior ao conectivo. Vejamos um exemplo de texto utilizado pelos pesquisadores (3) (MILLIS \& JUST, 1994, p.132):

(3) The elderly parents toasted their only daughter at the party [because] Jill had finally passed the exams at the prestigious university ${ }^{8}$.

\section{Probe word: toasted}

Os sujeitos participantes do experimento leram textos com e sem o conectivo because relacionando duas proposições (cada proposição era formada por uma oração, no caso do exemplo 3, toasted e passed) e tinham de responder, apertando o botão de verdadeiro ou falso, no computador, se a palavra-sonda havia aparecido ou não no texto que acabara de ler.

Os resultados encontrados mostraram que a existência de conectivos, para as sentenças experimentais com a palavra-sonda referente ao verbo contido na proposição 1 (a palavra-sonda aparecia depois de o sujeito ter lido todo o texto), facilitou a resposta referente à palavra-sonda.

Além disso, quando havia conectivo no texto o tempo de leitura para a palavra que seguia o conectivo foi menor. De acordo com os autores, estes marcadores textuais facilitaram a leitura porque manifestavam explicitamente o tipo de relação de coerência pretendido pelo autor do texto: "[...] the connective helped the interpretation of the second clause because the connective made the author's intended inter-clause ralation explicit, thereby reducing the need

\footnotetext{
${ }^{7}$ Mas (tradução nossa).

8 "Os pais idosos brindaram sua única filha na festa [porque] Jill finalmente passou os exames na prestigiada universidade". Palavra-sonda: bridaram (tradução nossa)
} 
for readers to research for an appropriate relation as they read statement 2 "9 (MILLIS \& JUST, 1994, p.143).

\section{Influência do tipo de relação de coerência e da frequência de uso no processamento de conectivos}

Sanders e Noordman (2000) investigaram a natureza da relação de coerência (problemasolução e lista) e a maneira como estas relações são manifestadas (explicitamente ou implicitamente).

A relação de coerência problema-solução (problem-solution) manifesta uma conexão causal entre proposições, já a de tipo list manifesta uma relação de adição (SANDERS \& NOORDMAN, 2000, p. 38 ${ }^{10}$ :

(4) It has been dangerous to cross that street for years. There is a solution for this problem: the city council has now decided to build a subway for pedestrians

(5) The city council has decided to build a subway for pedestrians. In addition new traffic lights will be installed nearby.

Os autores realizaram tarefa de leitura com os sujeitos participantes do experimento. Havia textos contendo conectivos e textos sem conectivos manifestando o tipo de relação de coerência (problem-solution ou list). Os resultados encontrados mostraram efeito significativo para o tipo de relação de coerência. Neste sentido, foram registrados menores tempos de leitura para sentenças alvo tipo problem-solution quando comparados ao tempo de leitura para sentença alvo do tipo list. Houve, também, efeito relacionado à existência de marcador linguístico relacional, pois o tempo de leitura para a sentença alvo na condição com marcador linguístico relacional implícito foi maior do que tempo de leitura para sentença alvo na condição com marcador relacional explícito ${ }^{11}$.

Traxler et.al (1997) encontraram, por meio de tarefa experimental utilizando rastreamento ocular, diferenças na leitura de textos com relação de coerência do tipo diagnostic e causal (TRAXLER et.al., 1997, p.483) ${ }^{12}$ :

(6) Heidi could imagine and create things because she won first prize at the art show.

(7) Heidi felt very proud because she won first prize at the art show.

Os resultados mostraram que os leitores tiveram maior dificuldade na leitura das sentenças do tipo diagnostic. Segundo os autores, a sentença (6) demanda mais tempo para ser processada por precisar de uma inferência para estabelecer a natureza da consequência- a segunda oração seria uma evidência plausível para que a primeira oração seja verdadeira-, já a sentença (7), do tipo causal, demanda menos tempo para ser processada porque o

\footnotetext{
9 “[...] o conectivo ajudou a interpretação da proposição 2 porque o conectivo tornou explícita a relação entre as orações intencionada pelo autor do texto, reduzindo assim a necessidade de os leitores pesquisarem uma relação apropriada ao lerem a proposição 2" (Tradução nossa) (MILLIS \& JUST, 1994, p.143)

10 "Tem sido perigoso atravessar essa rua por anos, há uma solução para este problema: o conselho municipal decidiu agora construir um metrô para pedestres." (tradução nossa)

"O conselho da cidade decidiu construir um metrô para pedestres. Além disso, novos semáforos serão instalados nas proximidades". (tradução nossa)

${ }^{11}$ A sentença alvo era formada pela proposição iniciada com o conectivo, por exemplo, no caso da sentença (5), a sentença alvo foi "In addition new traffic lights will be installed nearby."

12 "Heidi poderia imaginar e criar coisas porque ganhou o primeiro prêmio no show de arte". (tradução nossa).

"Heidi sentiu-se muito orgulhosa porque ganhou o primeiro prêmio no show de arte". (tradução nossa).
} 
processamento é mais simples. Neste caso, a segunda oração é uma causa plausível para o evento descrito na primeira oração.

Murray (1997) verificou, por meio de experimentos investigando o papel dos conectivos no processamento textual, o Princípio da Continuidade. Neste há a afirmação de que conectivos causais e aditivos proporcionam menor facilitação no processamento do que conectivos adversativos. Os conectivos causais e aditivos indicam continuidade no discurso enquanto os conectivos adversativos indicam descontinuidade. Segundo este princípio, leitores tendem a interpretar períodos, em narrativas, de maneira linear, sendo os eventos posteriores contínuos aos eventos anteriores. Textos com esta estrutura/conteúdo são lidos mais facilmente.

Os resultados dos experimentos realizados mostraram que na tarefa de completar períodos de textos sem conectivos, os leitores preferiram estabelecer, entre os períodos, relação causal.

Os leitores também participaram de uma tarefa on-line de leitura de textos com períodos relacionados por conectivos (aditivos, causais, adversativos) incongruentes ou sem conectivo. De maneira geral, a sentença-alvo de textos incongruentes com conectivo teve maior tempo de leitura do que a sentença-alvo de texto sem conectivo. Além disso, conectivos adversativos incongruentes causaram maior tempo de leitura do período após o conectivo incongruente.

Sobre o papel dos conectivos o autor afirma que "Se os leitores assumem, por padrão, que os eventos de texto são contínuos, os conectivos que sinalizam continuidade devem ter menos impacto no processamento on-line do que aqueles que sinalizam quebra de continuidade" (MURRAY, 1997, p.229). É o que acontece com textos aditivos e causais, que manifestam continuidade, e que não ocorre com textos adversativos.

A frequência de uso de conectivos foi investigada por Segui et.al. (1982). Os autores, por meio de pesquisa experimental, mostraram que houve correlação negativa entre frequência estimada e o tempo de reação do leitor, ou seja, quanto maior a frequência estimada da palavra, menor foi o tempo de reação do leitor para responder a pergunta referente à tarefa experimental.

Crosson et.al (2008) investigaram fatores que influenciam a compreensão de conectivos por crianças: familiaridade, frequência e hipótese da classe semântica. Os autores utilizaram tarefa experimental off-line, por meio de questionário utilizando textos com conectivos frequentes e familiares (houve aplicação de teste de familiaridade com crianças da mesma idade daquelas que realizaram o experimento). A hipótese da carga semântica trata do nível de dificuldade de compreensão de textos com base em relações de coerência. Neste caso, para Crosson et.al (2008), há relações semânticas mais fáceis e relações semânticas mais difíceis. A ordem de dificuldade (partindo da relação mais fácil para a mais difícil) é a seguinte: aditiva, contrastiva, temporal, causal e adversativa ${ }^{13}$.

Os resultados mostraram que houve relação entre familiaridade e dificuldade com o conectivo. Com base nas respostas dos alunos, o modelo criado pelos autores sugere que itens aditivos mais familiares, por exemplo, item and (palavra classificada como o maior grau de familiaridade), foram mais facilmente compreendidos do que itens aditivos menos familiares, como o item moreover (palavra com menor grau de familiaridade).

Somos seres textuais, compreender textos é uma atividade linguística fundamental para nos sentirmos inseridos em um mundo permeado de textos. Silfhout et.al (2014) apontam para a importância dos conectivos em processos de aprendizagem. Desta forma, a existência de conectivos tendem a beneficiar principalmente leitores com menor grau de instrução. Por isso

13 Diferente da relação adversativa, que sinaliza causalidade em relações de oposição ou contraste, segundo Crosson et.al. (2008), a relação semântica contrastiva é um tipo de relação aditiva, que manifesta excepcionalidade ou oposição, não havendo causalidade entre os segmentos conectados. Por exemplo: "Susan's favorite animal is a dog. In contrast, Carolina thinks cats are the best pets." (CROSSON et.al., 2008, p.608) ("O animal favorito de Susan é o cachorro. Em contraste, Carolina acha que os gatos são os melhores animais de estimação”, tradução nossa). 
os autores apontam para a importância da investigação experimental para embasar o design de textos educacionais eficientes. Em experimento off-line, por exemplo, os autores encontraram melhor desempenho em tarefas experimentais quando havia nos textos a presença de conectivos.

As pesquisas relatadas investigaram o papel dos conectivos no processamento de períodos e serviram de base para a nossa investigação sobre esses recursos de coesão, em português brasileiro.

\section{Experimento 1}

O experimento 1 teve como objetivo investigar a influência dos conectivos com função adversativa no processamento de períodos congruentes com a relação adversativa com base no tempo de leitura dos segmentos compositores do texto e no tempo de resposta à palavra-sonda, a partir da tarefa de leitura automonitorada (self-paced Reading) na modalidade moving window ${ }^{14}$.

A escolha dos conectivos utilizados nos experimentos e no teste de familiaridade se deu com base na frequência de uso inventariada no corpus da Linguateca (disponível em: https://www.linguateca.pt/) e em pesquisas funcionalistas baseadas em corpora (SILVA, 2005; BRITO, 2016; FOCHI \& ROCHA, 2011). Neste sentido, em uma gradação que varia em frequência de uso (maior, intermediária e menor), convergem as pesquisas sobre a primazia do conectivo mas quando a ideia é manifestar relações de coerência "contrárias à expectativa" (HALLIDAY \& HASAN, 1976, p.250). Depois, seguem os conectivos, em nível intermediário de frequência de uso, porém e $e$. O conectivo todavia é o recurso de coesão adversativo com menor frequência de uso (SILVA, 2005; BRITO, 2016). Silva (2005) analisou textos de 180 editoriais jornalísticos e encontrou o conectivo mas com o maior número de ocorrências (143), seguido por porém (36) e $e$ (35). O conectivo todavia foi encontrado 09 vezes.

Brito (2016) analisou o uso de conectivos adversativos em notícias de jornais dos séculos XX e XXI, totalizando 60 notícias em que encontrou 115 itens adversativos, sendo 66 ocorrências do conectivo mas, 20 do conectivo porém, 03 do conectivo $e$ e 01 ocorrência do conectivo todavia. É interessante notar que o conectivo $e$ foi encontrado em notícias de jornais do século XXI, além disso, o conectivo todavia só foi encontrado nos jornais do século XX.

Fochi e Rocha (2011) analisaram 107 textos produzidos por graduandos e encontraram 117 ocorrências do conectivo mas e 10 ocorrências do conectivo porém. Não foram produzidas relações entre proposições com as conjunções $e$ (em função adversativa) e todavia. Com base nas pesquisa acima elencadas, os cinco níveis que compõem a variável independente foram os seguintes:

a) Frequência de uso de conectivos adversativos (mas, porém, e, todavia, sem conectivo).

Basicamente investigamos o papel dos conectivos adversativos no processamento de períodos observando os tempos de leitura de textos compostos por duas proposições, sendo a segunda iniciada ou não pelo conectivo adversativo. Na tabela 1, por exemplo, para textos com conectivos, a proposição 1 era "Eva concluiu brilhantemente o texto,", a proposição 2 era "mas a edição ficou péssima na opinião dos leitores exigentes". A existência de textos sem conectivo, nas sentenças experimentais, teve como motivo comparar o efeito da existência ou ausência dos conectivos na leitura de graduandos e estudantes do ensino médio:

\footnotetext{
${ }^{14}$ Certificado de apresentação para a apreciação ética (CAAE): 94518418.6.0000.5188.
} 
Volume 15 - Número 2 - ago/dez de 2020

Tabela 1: segmentos analisados, pelo tempo de leitura, nos experimentos.

\begin{tabular}{|c|c|c|c|c|c|c|c|c|c|c|c|}
\hline $\begin{array}{l}\text { TIPO DE } \\
\text { TEXTO }\end{array}$ & SEG.1 & SEG.2 & SEG.3 & SEG.4 & SEG.5 & $\begin{array}{l}\text { SEG.6 } \\
\end{array}$ & SEG.7 & SEG. 8 & SEG.9 & SEG.10 & $\begin{array}{l}\text { PALAVRA- } \\
\text { SONDA }\end{array}$ \\
\hline $\begin{array}{l}\text { Texto com } \\
\text { conectivo }\end{array}$ & Eva & concluiu & $\begin{array}{l}\text { brilhante- } \\
\text { mente }\end{array}$ & o texto, & mas & a edição & ficou & péssima & $\begin{array}{l}\text { na } \\
\text { opinião }\end{array}$ & $\begin{array}{l}\text { dos } \\
\text { leitores. }\end{array}$ & CONCLUIU \\
\hline $\begin{array}{l}\text { Texto sem } \\
\text { conectivo }\end{array}$ & Eva & concluiu & $\begin{array}{l}\text { brilhante- } \\
\text { mente }\end{array}$ & o texto, & a edição & ficou & $\begin{array}{l}\text { péssi- } \\
\text { ma }\end{array}$ & $\begin{array}{l}\text { na } \\
\text { opinião }\end{array}$ & $\begin{array}{l}\text { dos } \\
\text { leitores }\end{array}$ & exigentes. & CONCLUIU \\
\hline
\end{tabular}

Fonte: elaboração própria

Analisamos, como podemos observar na tabela 1, três momentos da segunda proposição: a parte contendo o conectivo (segmento 5 de textos com conectivo); a parte inicial da proposição 2 (segmento 6 para textos com conectivos e segmento 5 para textos sem conectivo) e, finalmente, a parte que completa o sentido do texto, sendo manifestada pelo segmento 8 em textos com conectivos e segmento 7 para textos sem conectivo. Assim, as variáveis dependentes do experimento foram o tempo de leitura desses segmentos e o tempo de resposta à palavra-sonda (segmento 11$)^{15}$.

$\mathrm{O}$ design do experimento é $5^{1}$ gerando, em cada conjunto experimental, as seguintes condições experimentais que foram utilizadas no experimento 1 e experimento $2^{16}$ :

\section{1) Texto com conectivo mas (TCM):} leitores"

"Eva/ concluiu/ brilhantemente/ o texto,/ mas/ a edição/ ficou/ péssima/ na opinião/ dos

\section{2) Texto com conectivo porém (TCP):} dos leitores"

"Eva/ concluiu/ brilhantemente/ o texto,/ porém/ a edição/ ficou/ péssima/ na opinião/

3) Texto com conectivo $e$ (TCE):

"Eva/ concluiu/ brilhantemente/ o texto/ $\boldsymbol{e}$ / a edição/ ficou/ péssima/ na opinião/ dos leitores"

4) Texto com conectivo todavia (TCT): dos leitores"

"Eva/ concluiu/ brilhantemente/ o texto,/ todavia/ a edição/ ficou/ péssima/ na opinião/

\section{5) Texto sem conectivo (TNC):}

"Eva/ concluiu/ brilhantemente/ o texto,/ a edição/ ficou/ péssima/ na opinião/ dos leitores/exigentes".

\subsection{Método}

\section{Participantes}

Participaram do experimento 32 graduandos, da Universidade Federal da Paraíba, todos falantes do PB, com média de idade de 24 anos.

\section{Material}

\footnotetext{
${ }^{15}$ As palavras-sonda das sentenças experimentais eram formadas pelo verbo constante na proposição 1 .

16 Foram controladas as quantidades de sílabas de cada segmento evitando, portanto, o fator extensão do constituinte.
} 
O material consistiu de cinco conjuntos experimentais, com 20 sentenças experimentais e 40 sentenças distratoras. Cada conjunto experimental foi composto por cinco condições, com quatro sentenças experimentais por condição.

Cada sujeito participante da pesquisa leu um conjunto experimental composto, no total, por 60 sentenças. Por meio do quadrado latino todas as condições foram lidas pelos participantes da pesquisa, entretanto, cada conjunto era formado por itens experimentais diferentes.

Para a aplicação do experimento utilizamos um notebook Lenovo (modelo 81CC) em conjunto com o programa Psychopy (PIERCE, 2009), no qual o experimento foi programado e rodado.

\section{Procedimento}

O experimento, executado por meio do programa Psychopy, utilizou uma técnica online de leitura automonitorada (self-paced reading), na modalidade moving window, em que os participantes monitoraram sua própria leitura em frente à tela do computador e ao teclado, em uma sala isolada no Laboratório de Processamento Linguístico- LAPROL ${ }^{17}$.

A tarefa consistiu em ler, em velocidade natural, sentenças divididas em 10 segmentos. O segmento 11 era composto pela palavra-sonda. Os participantes foram testados individualmente e todos foram primeiramente orientados oralmente pelo experimentador e depois por instruções que apareceram na tela do computador. Os participantes foram informados de que no final de cada texto apareceria uma palavra (palavra-sonda). A tarefa era responder, apertando a tecla sim ou não (no teclado) se aquela palavra estava ou não no texto lido.

Todos os participantes realizaram uma tarefa treino que simulava o que deveriam fazer quando estivessem sozinhos realizando a tarefa experimental. A tarefa tinha início quando o leitor teclava a barra de espaço no computador e via o sinal "+" que aparecia (justamente na parte localizada à esquerda da tela do computador) para indicar ao leitor para onde ele deveria direcionar o olhar na tela. Teclando novamente na barra de espaço, desaparecia o sinal de "+" e aparecia o primeiro segmento, apertando novamente a barra de espaço, outro segmento aparecia, à direita do segmento anterior, que automaticamente desaparecia da tela. O mesmo acontecia para os segmentos seguintes até o último segmento (final do período), sinalizado com um ponto final, localizado na extremidade direita da tela do computador.

Após o segmento final, o leitor apertava a barra de espaço e então aparecia, no centro da tela, uma palavra. Neste momento o participante deveria responder se a palavra apareceu ou não na sentença que acabara de ler, apertando a tecla S (para responder SIM) ou a tecla N (para responder $\mathrm{NÂO}$ ). Estes procedimentos se repetiam até o leitor completar a leitura de todas as sentenças formadoras do experimento.

Os tempos de todos os 10 segmentos foram gravados e também o tempo referente à opção de resposta (SIM ou NÃO). Depois de completarem a tarefa de leitura os participantes responderam a um questionário sobre perfil leitor e a um teste de familiaridade. Todos os participantes foram orientados sobre estas atividades.

O questionário do perfil do leitor constava de algumas perguntas para termos acesso à relação do leitor com a leitura. Uma das questões, por exemplo, era sobre a quantidade de livros existentes na residência dos participantes da pesquisa, em outra questão perguntamos sobre a quantidade de horas dedicadas à leitura. No teste de familiaridade os leitores foram orientados a classificar os conectivos, que relacionavam textos, por meio de valores, que variavam de 1 a

17 O software do Psychopy pode ser baixado gratuitamente por meio do endereço eletrônico: https://www.psychopy.org/ e http://www.cchla.ufpb.br/laprol/language/pt/ 
Volume 15 - Número 2 - ago/dez de 2020

5 , em que a nota 5 deveria ser dada ao conectivo considerado mais familiar e a nota 1 ao conectivo menos familiar ${ }^{18}$.

\subsection{Resultados e Discussão ${ }^{19}$}

Não encontramos efeito principal de frequência de uso de conectores adversativos no segmento 5, na análise por participante (ANOVA: $\mathrm{F} 1(1,31)=0,25, \mathrm{p}>0,05$ ) e na análise por item (ANOVA: $F 2(1,19)=0,43, p>0,05)^{20}$. Lembremos que o segmento 5 , em textos com conectivos, era formado pelos próprios conectivos mas, porém, e e todavia.

Encontramos efeito principal para frequência de uso de conectores adversativos quando comparamos a parte inicial da proposição $2 \mathrm{em}$ textos com conectivo (segmento 6) com textos sem conectivo (segmento 5) na análise por participante (ANOVA: F1 $(1,31)=27,78, p<0,05$ ), assim como na análise por item (ANOVA: F2 $(1,19)=16,85, \mathrm{p}<0,05)$. O tempo de leitura foi significativamente menor para as palavras que eram antecedidas pelo conectivo (gráfico 1).

Além disso, quando observamos somente os textos com conectivos, o teste-t revelou que palavras antecedidas por conectivos mas e $\boldsymbol{e}$ tiveram vantagem no tempo de leitura quando comparamos ao tempo de leitura para palavras que seguiam os conectivos porém e todavia: $\mathrm{TCM} \times \mathrm{TCP}=(\mathrm{t}(31)=5,76 ; \mathrm{p}<0,05) ; \mathrm{TCM} \times \mathrm{TCT}=(\mathrm{t}(31)=6,69 ; \mathrm{p}<0,05) ; \mathrm{TCE} \times \mathrm{TCP}=(\mathrm{t}(31)$ $=7,75 ; \mathrm{p}<0,05) ; \mathrm{TCE} \times \mathrm{TCT}=(\mathrm{t}(31)=7,66 ; \mathrm{p}<0,05)$.

Gráfico 1: Tempos de leitura, em milissegundos, da parte inicial proposição 2 (Segmento 6 para as condições TCE, TCM, TCP, TCT e segmento 5 para a condição TNC), conforme a análise por participante (F1).

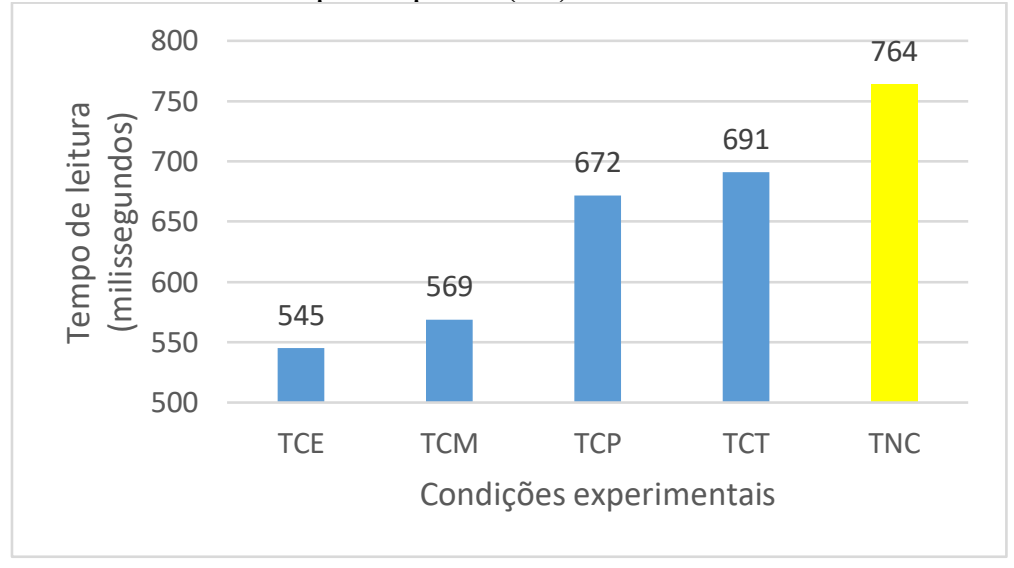

Fonte: elaboração própria.

No gráfico 2, podemos observar efeito principal para tipo de texto, pois textos com conectivo facilitaram a leitura do segmento que completa o sentido do texto. Encontramos menores tempos de leitura para as condições com conectivo (segmento 8) quando comparamos com a condição sem conectivo (segmento 7) na análise por participante (ANOVA: F1 $(1,31)=$ $6,91, \mathrm{p}<0,05)$ e na análise por item (ANOVA: F2 $(1,19)=8,34, \mathrm{p}<0,05)$.

\footnotetext{
18 Os questionários sobre perfil de leitor e o teste de familiaridade foram programados no Google forms. As respostas dos sujeitos participantes também foram registradas pelo Google forms (https://www.google.com/intl/ptBR/forms/about/)

${ }^{19}$ Os dados outliers via Boxplot que foram retirados do EXP.1 ficaram abaixo dos $4 \%$ do total de dados.

${ }^{20}$ Depois de realizarmos o experimento os dados encontrados precisaram passar por um pacote estatístico. Para isso utilizamos a interface Action que tem a mesma base de cálculo estatístico do programa $\mathrm{R}$ e que pode ser baixado, mediante pagamento, na página virtual: http://www.portalaction.com.br/
} 
Gráfico 2: Tempos de leitura, em milissegundos, para a parte da proposição 2 que completa o sentido do texto: segmento 8 para textos com conectivo (TCE, TCM, TCT, TCP) e segmento 7 para textos sem conectivo (TNC), conforme análise por participante (F1)

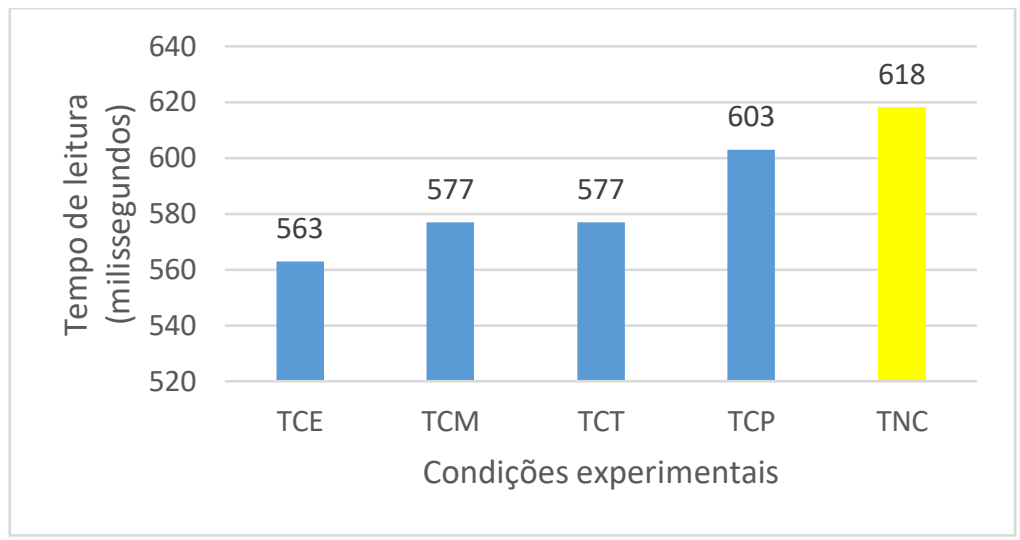

Fonte: Elaboração própria.

Com relação à tarefa-sonda, obtivemos efeito principal para tipo de texto (com conectivo/sem conectivo) na análise por participante (ANOVA: $F 1(1,31)=6,49, p<0,05)$ e na análise por item (ANOVA: F2 $(1,19)=2,39, \mathrm{p}<0,05)$. Desta forma, os sujeitos participantes da pesquisa responderam mais rapidamente à tarefa-sonda depois de lerem textos com conectivo quando comparamos com o tempo de reposta para textos sem conectivos.

Os resultados parecem corroborar que a existência de conectivos promove facilitação na leitura de períodos, ou seja, se nós hipotetizamos a respeito do texto (sobre sua estrutura e conteúdo), os conectivos nos ajudam nesse processo. Este tipo de comportamento está relacionado, também, com a predição sobre a estrutura textual. Assim, a função de segmentador textual parece ser real em termos psicológicos (NOORDMAN e VONK, 2014).

Os menores tempos de leitura para segmentos finais de textos com conectivo demonstram que a existência de conectivos, manifestando explicitamente qual tipo de relação a ser elaborada entre as proposições formadoras do texto, ajuda o leitor na compreensão textual (MILLIS e JUST, 1994). De certa forma, temos a função de integrador textual sendo demonstrada pelo comportamento linguístico do leitor ao ler segmentos finais da proposição 2 .

Ainda sobre o processamento da parte da proposição 2 que completa o sentido do texto, mais especificamente sobre o processamento do segmento 7, para a condição $\mathrm{TNC}$, a falta de conectivo provocou um prejuízo no processamento. Se a causalidade é o modo de interpretação preferido (DIJK \& KINTSCH, 1983; ALTMAN \& MIRKOVIC,2009), a falta de um conectivo fez com que os leitores processassem as proposições do texto sem conectivo (TNC), provavelmente, como uma relação causa-consequência. Percebendo que a expectativa criada a respeito do andamento do texto não foi corroborada, o leitor possivelmente analisou novamente a relação entre as proposições, e, nesse sentido, notou que se tratava de um caso de relação de coerência adversativa.

Os resultados indicam que o processamento de períodos com relação de coerência adversativa é influenciado pela frequência de uso de conectivos. Encontramos menores tempos de leitura para palavras que seguiam os conectivos com maior frequência de uso (mas; $e$ ) quando comparamos com a leitura da parte do texto que seguia conectivos com menor frequência de uso (porém; todavia).

$\mathrm{Na}$ tarefa offline referente ao teste de familiaridade realizado pelos sujeitos participantes do experimento 1 os sujeitos foram instruídos a classificarem a familiaridade com o conectivo que aparecia nos diversos textos a serem lidos. A classificação de familiaridade variava de cinco, nota máxima, até 1 , nota mínima. O modelo de regressão multinomial para o teste de 
Volume 15 - Número 2 - ago/dez de 2020

familiaridade de leitores graduandos mostrou que a probabilidade de o leitor dar nota 5 a todas as formas de conectivos adversativos utilizados nos textos é maior do que a probabilidade de dar nota inferior a 5. Portanto, os conectivos adversativos são, em geral, familiares aos leitores participantes do experimento, no entanto, mostraram também que o conectivo mas foi considerado mais familiar em relação aos outros conectivos testados, o que converge com a frequência de uso observada nos estudos de corpora.

\section{Experimento 2}

O experimento 2 teve como objetivo investigar a influência dos conectivos com função adversativa no processamento de textos congruentes na leitura de estudantes do ensino médio.

$\mathrm{O}$ design experimental foi o mesmo do experimento 1 .

\subsection{Método}

\section{Participantes}

Participaram do experimento 24 estudantes do ensino médio, do IFPB, Campus Cabedelo, todos falantes do português brasileiro, com média de idade de $15 \operatorname{anos}^{21}$.

\section{Material}

Mesmo material do experimento 1.

\section{Procedimento}

O procedimento foi o mesmo utilizado na realização do experimento 2, entretanto, neste experimento solicitamos autorização do Instituto Federal da Paraíba (IFPB), campus Cabedelo, para a realização da pesquisa e também autorização dos pais dos estudantes que participaram do experimento.

O experimento foi realizado em uma sala isolada do IFPB, campus Cabedelo, cedida pela professora Alessandra Ferreira.

\subsection{Resultados e discussão}

Assim como no experimento 1, não encontramos efeito principal para frequência de uso de conectivos, no segmento 5 , onde se encontram os conectivos das frases testadas, na análise por participante (ANOVA: F1 $(1,23)=0,21, \mathrm{p}>0,05)$ e na análise por item (ANOVA: F2 $(1,19)$ $=0,21, \mathrm{p}>0,05)$.

Encontramos efeito principal para frequência de uso de conectivos na análise por participante (ANOVA: F1 $(1,23)=19,54, \mathrm{p}<0,05)$ e na análise por item (ANOVA: F2 $(1,19)=$ $17,72, \mathrm{p}<0,05$ ), para a parte inicial da proposição 2 (segmento 6 e segmento 5 , com e sem conectivo respectivamente). O tempo de leitura foi significativamente menor para as palavras que eram antecedidas pelo conectivo.

Ainda analisando o segmento 6 e o segmento 5, o teste-t revelou que todas as condições com conectivo tiveram tempos de leitura significativamente menores quando comparamos com a condição sem conectivo, com exceção para a condição com o conectivo todavia $(\mathrm{t}(23)=0,65$; $\mathrm{p}>0,05)$, o que divergiu do resultado com os universitários. Desta forma, o tempo de leitura

\footnotetext{
${ }^{21} \mathrm{https}: / /$ www.ifpb.edu.br/cabedelo
} 
Volume 15 - Número 2 - ago/dez de 2020

para a condição TCM foi significativamente menor que o tempo de leitura da condição TNC $(\mathrm{t}(23)=6,39 ; \mathrm{p}<0,05)$, assim como quando comparamos a condição TCE com TNC (t(24) $=11,26 ; \mathrm{p}<0,05)$, a condição TCP com a condição TNC $(\mathrm{t}(23)=3,93 ; \mathrm{p}<0,05)$, conforme demonstrado no gráfico 3 .

Gráfico 3: segmento 6 para as condições TCM, TCP, TCE, TCT e segmento 5 para a condição TNC, conforme a análise por participante (F1).

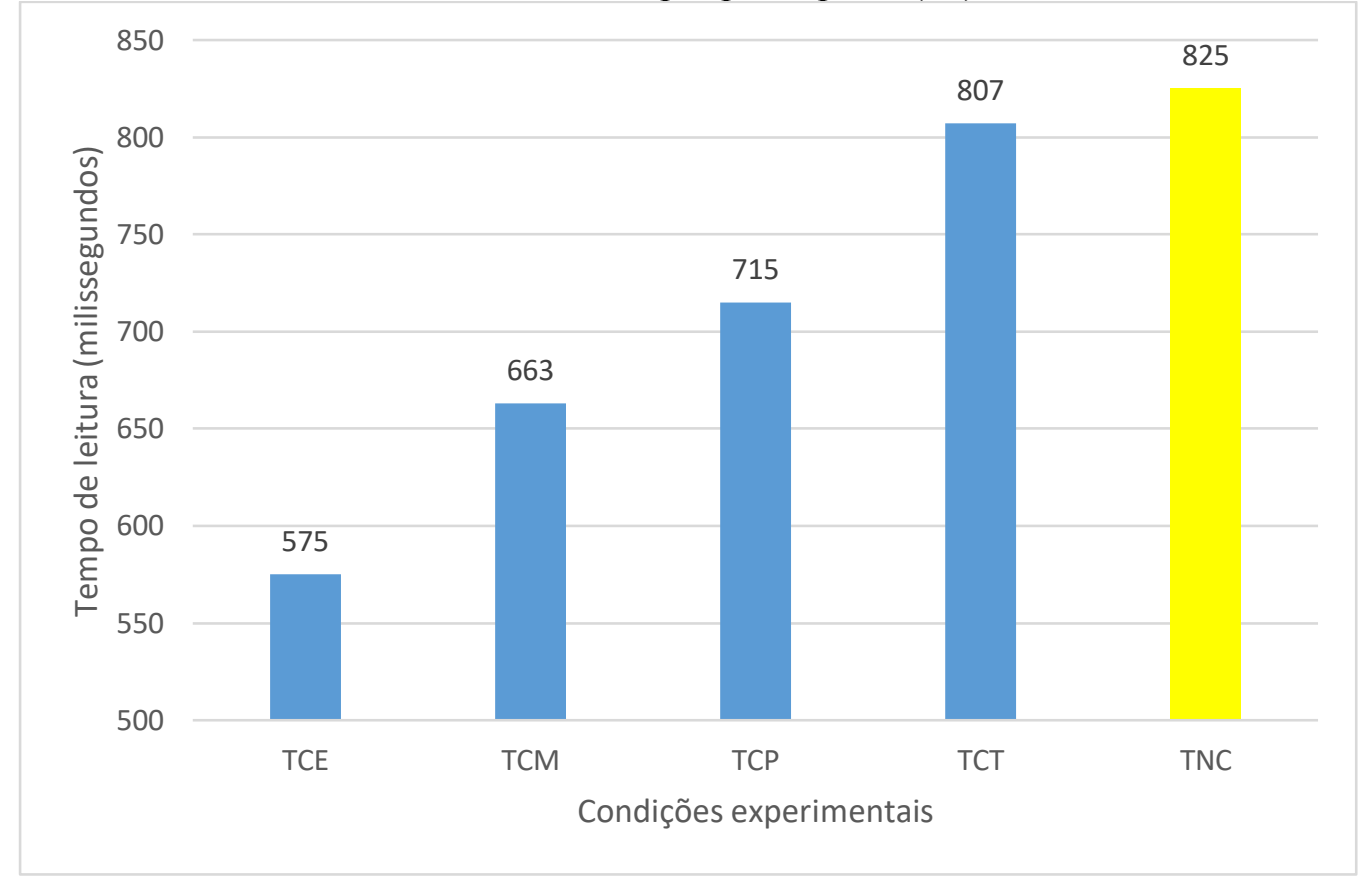

Fonte: elaboração própria.

Ainda analisando somente os conectivos, o marcador relacional mas facilitou mais a leitura do segmento 6 do que os conectivos porém $(\mathrm{t}(24)=1,82 ; \mathrm{p}<0,07)$, todavia $(\mathrm{t}(24)=4,98$; $\mathrm{p}<0,05) 103$.

Encontramos efeito principal para tipo de texto na análise por participante (ANOVA: $\mathrm{F} 1(1,23)=8,32, \mathrm{p}<0,05)$ e na análise por item (ANOVA: $\mathrm{F} 2(1,19)=8,73, \mathrm{p}<0,05)$ para os segmentos que completam o sentido do texto (segmento 7 e segmento 8). Desta forma, conforme observado no gráfico 4, textos com conectivo (segmento 8) facilitaram a leitura do segmento que completa o sentido do texto, pois encontramos menores tempos de leitura para as condições com conectivo quando comparamos com a condição sem conectivo (segmento 7). Além disso, quando comparamos somente as condições TCT x TNC não encontramos de novo diferença significativa no tempo de leitura $(\mathrm{t}(24)=1,63 ; \mathrm{p}>0,05)$. 
Volume 15 - Número 2 - ago/dez de 2020

Gráfico 4: Tempos de leitura (em milissegundos) para a parte da proposição 2 que completa o sentido do texto, segmento 8 para as condições com conectivo e do segmento 7 para textos sem conectivo (TNC), conforme análise por participante (F1)

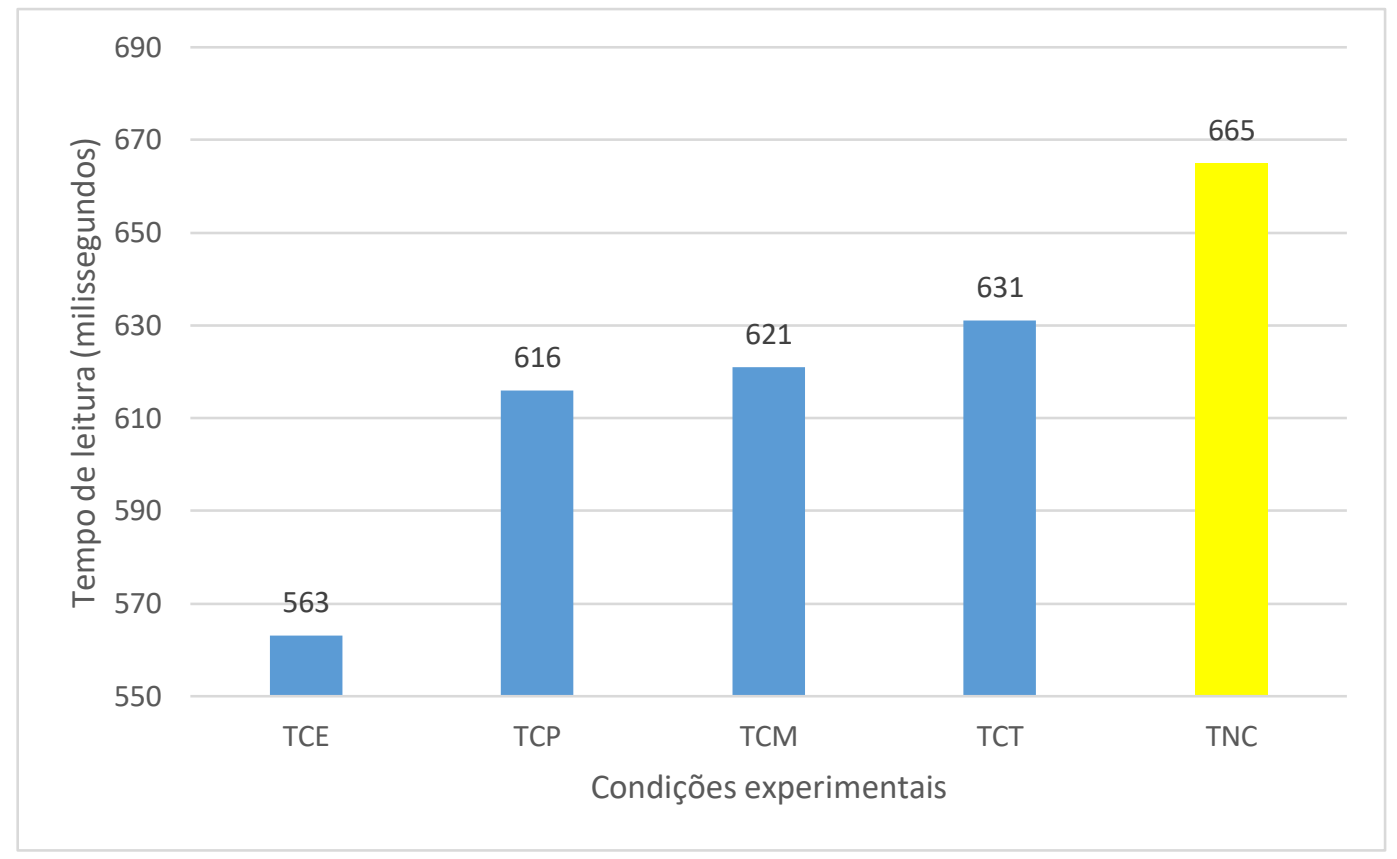

Fonte: elaboração própria.

Encontramos efeito significativo para presença ou ausência de conectivos adversativos no teste-sonda na análise por participante (ANOVA: F1 $(1,23)=3,12, \mathrm{p}<0,05$ ) e na análise por item (ANOVA: F2 $(1,19)=3,31, \mathrm{p}<0,05)$. De maneira geral, houve menores tempos de resposta para textos com conectivos quando comparamos aos textos sem conectivo.

Os resultados confirmaram a facilitação na leitura proporcionada pela existência de conectivos corroborando os resultados dos experimentos 1 . Entretanto, nem todos os conectivos facilitaram a leitura do texto. Não encontramos diferença significativa na leitura da proposição que seguia o conectivo todavia quando comparamos com a proposição não antecedida por conectivo. Apesar de, no teste de familiaridade, a probabilidade de os estudantes do ensino médio classificarem com nota máxima todos os conectivos adversativos, a probabilidade de leitores do ensino médio darem nota máxima ao conectivo todavia foi menor quando comparamos com a probabilidade de os leitores graduandos darem nota 5 a este conectivo. $\mathrm{O}$ conectivo todavia parece ser mais familiar aos graduandos do que aos alunos do ensino médio.

O questionário sobre o perfil do leitor forneceu informações interessantes que podem ser relacionadas a menor familiaridade dos leitores do ensino médio com conectivos menos frequentes. Os leitores do ensino médio dedicam menos horas à leitura quando comparamos com o tempo de dedicação à leitura de estudantes graduandos. Além disso, os leitores graduandos possuem mais livros em casa do que leitores do ensino médio ${ }^{22}$.

${ }^{22} \mathrm{O}$ questionário sobre perfil do leitor revelou que 53\% dos leitores graduandos dedicam mais de três horas de leitura durante uma semana. $25 \%$ dos estudantes do ensino médio fazem o mesmo.

Também perguntamos a quantidade de livros disponíveis nas residências dos sujeitos participantes dos experimentos. $44 \%$ dos graduandos possuem mais de 50 livros, enquanto $8 \%$ dos estudantes do ensino possuem mais de 50 livros em suas casas. 


\section{Conclusões}

Podemos afirmar que os conectivos facilitam o processamento textual, pois encontramos, nos experimentos 1 e 2, menores tempos de leitura em segmentos posteriores aos conectivos quando comparamos os mesmos segmentos em textos sem conectivos. Parece ser real, em termos psicológicos, a função de segmentador textual do conectivo. É como se o leitor soubesse, a partir da leitura do conectivo, as possibilidades estruturais e de certa maneira, lógico-semânticas da proposição que o segue.

Nossos resultados indicam que os menores tempos de leitura para segmentos finais em textos com conectivos podem manifestar a facilitação na leitura de segmentos que estão de acordo com as hipóteses efetivas construídas pelo leitor com base na pista sugerida pelo conectivo existente no texto.

O modelo estratégico de processamento prevê que leitores constroem hipóteses efetivas sobre a estrutura e conteúdo do texto com base no que está manifestando explicitamente no texto e em seu conhecimento. Há um diálogo entre as funções desempenhadas pelo conectivo no texto (segmentar, integrar e promoção de inferências) e a criação de hipóteses efetivas sobre a estrutura e conteúdo textual, já que a função de segmentar está relacionada à estrutura do texto e a função de integrar está relacionada ao conteúdo do texto.

Essa maior integração textual promovida pela existência dos conectivos também dialoga com a hipótese de reativação, pois textos com conectivos reativam em maior grau partes do texto antecedentes ao conectivo, quando comparamos com textos sem conectivo. Parece que os conectivos modulam o nível de ativação dos constituintes textuais, pelo menos, foi o que indicou os menores tempos de respostas à tarefa-sonda nos experimentos 1 e 2 para textos com conectivos quando comparamos aos textos sem conectivo.

A existência de conectivo adversativo parece ser fundamental para que o leitor hipotetize corretamente sobre o conteúdo textual. Relações de coerência adversativas precisam de um conectivo que instrua o leitor a criar uma hipótese diferente da que normalmente seria construída. Neste caso, seria uma relação default de causa-consequência, por exemplo. Além disso, a relação de coerência adversativa entre proposições textuais foi influenciada pela frequência de uso do conectivo. Conectivos com maior frequência de uso facilitam mais a leitura do que conectivos com menor frequência de uso.

A aprendizagem escolar é fundamentada em textos, muitas vezes escritos. Compreender o papel dos conectivos no exato momento da leitura percebendo o efeito de facilitação promovido por eles pode significar embasamento para construção de textos didáticos com estes recursos de coesão. Neste sentido, a psicolinguística experimental pode auxiliar processos de aprendizagem nas escolas. A aplicação de experimento (on-line e off-line) com alunos com foco nos conectivos, por exemplo, como fizemos neste trabalho, pode indicar procedimentos relacionados a habilidades leitoras que, se explorados de forma explícita em posteriores intervenções, permitem a observação se haverá mudança no comportamento linguístico desses alunos leitores. A ideia é de que a partir dos assuntos/exercícios executados pelo professor durante o período de ensino sobre recursos de coesão, em conjunto com a exploração metacognitiva desses recursos via experimentos, podemos auxiliar os professores na avaliação sobre as relações de coerência dominadas pelos alunos e se algum tipo de intervenção pode promover maior familiaridade dos alunos com essas relações e alguma mudança em parte de suas habilidades leitoras.

O mapeamento dessas habilidades leitoras, em relação à articulação sentencial, pode dar subsídios para ações pedagógicas que criem maior consciência metalinguística e, consequentemente, consigam melhorar a habilidade dos alunos na leitura e também na construção dos textos. Experimentos de investigação sobre o processo de compreensão de textos pelos discentes podem ser realizados por meio de tarefa de leitura automonitorada que 
tem baixo custo e podem ser aplicados em escolas com relativa facilidade. Parceria entre escolas e universidades podem alavancar o uso da metodologia experimental no processo de ensino/aprendizagem. Temos bons exemplos desse tipo de parceria na UFRJ, por exemplo, com o trabalho do Laboratório de Eletroencefalografia e rastreamento ocular (LER) ${ }^{23}$ que mostraram resultados positivos nesse tipo de mapeamento associado a intervenção posterior (MAIA, 2019).

A Psicolinguística pode oferecer a metodologia experimental e as análises psicolinguísticas para que o professor tenha uma visão mais detalhada das necessidades dos alunos e dos progressos relacionados aos conteúdos ministrados em disciplinas como a de língua portuguesa. Pesquisas experimentais tratam de assuntos caros à área educacional. Neste sentido, há que se apoiar a divulgação de pesquisas experimentais e fomentar a translação entre achados da Psicolinguística e a Educação.

\section{Referências}

ALTMAN, Gerry T. M.; MIRKOVIC. Jelena. Incrementality and Prediction in Human Sentence Processing. Cognitive Science, v.4, n.33, p.583-609, 2009.

BRITO, Isabel Pauline Lima de. Conectores adversativos em textos jornalísticos sobre futebol: análise funcionalista em perspectiva histórica. 113f. 2016.Dissertação (Mestrado em Linguística) CROSSON, A., LESAUX, N., \& MARTINIELLO, M. Factors that influence comprehension of connectives among language minority children from Spanish-speaking backgrounds. Applied Psycholinguistics, v. 29, n. 4, p.603-625, 2008.

DIJK, Teun A. van; KINTSCH, Walter. Strategies of Discourse Comprehension. New York: Academic Press, 1983, 413p.

DIJK, Teun A. van. From Text Grammar to Critical Discourse Analysis. New Jersey: Lawrence Erlbaum Associates, 1981, 309 p.

FOCHI, Eliana Magrini; ROCHA, Celso Fernando. Usos de conectivos em língua portuguesa na produção textual de estudantes universitários. Antares: letras e humanidades, Caxias do Sul, n. 5, p. 77-91, 2011.

HASAN, Ruqaiya; HALLIDAY, M. A. K. Cohesion in English. London: Longman, 1976, 392 p.

KOCH, I. G. V.; TRAVAGLIA, Luiz Carlos. A coerência textual. 17. ed. São Paulo: Contexto, 2009.

MAIA, Marcus (org.). Psicolinguística e Metacognição na Escola. São Paulo: Ed. Mercado de Letras, 2019.

MARCUSCHI, Luiz Antônio. Produção textual, análise de gêneros e compreensão. São Paulo: Parábola Editorial, 2008.

MIILIS, Keith K; JUST, Marcel A. The influence of connectives on sentence comprehension. Journal of Memory and Language, v.33, n.5, p. 128-147, 1994.

MURRAY, John D. Connectives and narrative text: The role of continuity. Memory \& Cognition, v. 25, n.2, p.227-236, 1997.

PEIRCE, J.W. Generating stimuli for neuroscience using PsychoPy. Frontiers in Neuroinformatics, v.2, p.1-8, 2009.

SANDERS, Ted J. M.; NOORDMAN, Leo G.M. The role of coherence relations and their linguistic markers in text processing. Discourse Processes, v. 29, p.37-60, 2000.

SEGUI, Juan; MEHLER, Jacques; FRAUENFELDER, Uli; MORTON, John. The word frequency and effect and lexical access. Neuropsychologia, v.20, n. 6, p. 615-627, 1982.

\footnotetext{
${ }^{23} \mathrm{http}: / / \mathrm{www}$. ler.letras.ufrj.br/quem-somos.html
} 
SILFHOUT, Gerdineke V.; VERMEUL, Jacqueline-Evers; SANDERS, Ted J.M. Connectives as Processing Signals: How Students Benefit in Processing Narrative and Expository Texts. Discourse Processes, v.52, n.1, p.47-76, 2015.

SILVA, Camilo Rosa. Mas tem um porém: mapeamento funcionalista da oposição e seus conectores em editoriais jornalísticos. 287 f. 2005. Tese (doutorado em Linguística)

TRAXLER, Matthew J.; BYBEE, Michael D.; PICKERING, Martin J. Influence of Connectives on language comprehension: Eye-tracking evidence for Incremental Interpretation. The Quarterly Journal of Experimental Psychology, v.50, p. 481-497, 1997.

VONK, W.; NOORDMAN, L.G.M. On the control of inferences in text understanding. In: BALOTA, D.A.; FLORES D'ARCAIS, G. B.; RAYNER, K. Comprehension processes in reading. Nova Jersey: Lawrence Erlbaum Associates, 2012, p. 471-488. 